\title{
NORCIA AND AMATRICE: A COMPARISON OF THE TWO HISTORIC CENTRES' PERFORMANCE UNDER THE CENTRAL ITALY EARTHQUAKE SEQUENCE
}

\author{
V. Putrino ${ }^{1}$, D. D'Ayala ${ }^{2}$ \\ ${ }^{1}$ Civil Environmental and Geomatic Engineering Department \\ University College London (UCL) \\ valentina.putrino.14@ucl.ac.uk \\ ${ }^{2}$ Civil Environmental and Geomatic Engineering Department \\ University College (UCL) \\ d.dayala@ucl.ac.uk
}

\begin{abstract}
The seismic sequence started on the $24^{\text {th }}$ of August 2016 and concluded on January 2017 affected four region of Central Italy causing casualties, widespread damage to residential and heritage buildings and prolonged disruption. Among the many municipalities impacted by the seismic events, the towns of Amatrice and Norcia suffered the major losses.

Although many similarities can be found in their urban layouts and comparison can be made in terms of building materials, techniques and periods of construction, epicentral distances from the fault of the relevant seismic events and categorization in terms of seismic zonation, the significant shaking alone cannot justify the severe damage extent observed in Amatrice in comparison to the very limited one recorded in Norcia.

The purpose of this paper is to investigate the different behavior of the two urban settlements of Norcia and Amatrice under the relevant shakings, and to discuss the different damage extents to their residential urban fabrics considering the specific structural features and vulnerability factors. To accomplish this, a set of building data collected in Norcia during the EEFIT individual research mission carried out in September 2017, is first analyzed using the vulnerability assessment method FaMIVE; an extrapolation of the same data set is then 're-adjusted' in terms of material characteristics and strengthening elements to resemble the building stock of Amatrice: this is done on the basis of site observation collected by the authors during the 2016 Central Italy EEFIT mission. From the output of the FaMIVE procedure, capacity curves are derived and compared with the spectra of the main shocks of the seismic sequence. Cloud of performance points are generated for each event to be used to determine fragility curves, representative of the percentage of buildings undergoing certain damage levels under the specific seismic scenario. A discussion on the obtained results and the capability of the method to represent the observed damage extents concludes the paper.
\end{abstract}

Keywords: Seismic vulnerability, Historic Residential Masonry Structures. 


\section{INTRODUCTION}

The seismic sequence that hit the Central Italy area within the four regions of Abruzzo, Marche, Lazio and Umbria from August $24^{\text {th }}, 2016$ to January $18^{\text {th }}, 2017$ was severely disruptive in terms of damage to historic residential buildings and heritage structures and very onerous in the consequent death toll. Within the time frame of the sequence, nine events have been recorded with magnitude greater than 5 , three of which considered particularly devastating for the extensive damage they caused to sixteen municipalities which experienced a cumulative European Macroseismic Scale (EMS '98, Grunthal, 1998) IEMS $\geq$ IX [1].

The sequence started with a $\mathrm{M}_{\mathrm{w}} 6.2$ event, with epicentre $5.6 \mathrm{~km}$ from the town of Accumoli: as a consequence of the shaking, the near town of Amatrice was almost completely razed to ground and nearly 300 people died. Two other main events occurred on $26^{\text {th }}$ and $30^{\text {th }}$ of October with epicentres located respectively $18.40 \mathrm{~km}$ and $7.8 \mathrm{~km}$ from the town of Norcia, the second of which, with a magnitude $\mathrm{M}_{\mathrm{w}} 6.5$, was the stronger event ever occurred in Italy after the Irpinia earthquake in 1980 [2]. As a consequence, most of Norcia's cultural heritage buildings were severely damaged, while many residential buildings experienced structural damage.

Several factors can be considered influential in the stark difference in response of the masonry building stock in the two towns. According to the published shake maps [2], and as discussed further in section 4, the seismic demand for the first event was considerably larger in Amatrice for stiffer structures, than in Norcia. Although the local soil is assigned the same class B according to EC8 [3] the topography of the two towns is substantially different, with Amatrice laid out at the top of a hill, while Norcia lays in a valley, contributing to substantial differences in amplification of the seismic shaking [4].

The 2016 sequence took place in a territory with a long history of destructive earthquakes, and historic events with similar patterns of shaking are recorded. Evidence proving that both Amatrice and Norcia have been heavily hit by severe shakings date back to the $14^{\text {th }}$ century [5] and are documented through the numerous instances of repair and reconstruction that their historic centres have undergone [6]. Indeed, after the $1859 \mathrm{I}_{\mathrm{o}} 8-9 \mathrm{MCS}, \mathrm{M}_{\mathrm{w}} 5.7$ Norcia earthquake a manual of "good a-seismic" building practice was produced for Norcia's recovery. Following this, Norcia's urban fabric and its buildings underwent other systematic strengthening projects, as a result of regional laws enacted after more recent seismic events [6]. A similar process did not occur in Amatrice, even though it was recognized as a seismic territory in 1915 and classified in zone 2 in 1927, but construction was not subject to any specific seismic building regulation until 1984 when, following the enactment of the first Italian seismic hazard map, the town was classified as seismic zone 2, to be later upgraded to seismic zone 1 in 2003 [7]. This notwithstanding the building stock in the historic centres of the two towns has substantial similarities in terms of building size and geometry, while quality of materials, workmanship and extent and type of retrofitting differed markedly as discussed in [7] and illustrated in section 3.

An important feature of this sequence was the sustained or increased magnitude of the subsequent events producing strong shaking and causing cumulative damage to masonry buildings. Research on effects of aftershocks has focused on steel, RC or timber frame structures ([9][10][11], respectively). The common assumptions are that the aftershocks will be of lesser magnitude of the main shock, thus implying that a Markovian approach can be used [12], and of shorter duration, thus becoming a function of the time elapsed after the mainshock [13]. Hence these models might not be directly applicable to the Central Italy 2016 sequence.

The effect of repeated event for masonry structure has been studied by [14]. For the Central Italy 2016 sequence, the empirical evidence of such effects has been reported by [1], [15] and [16]. However, to the authors knowledge, such effect has not been quantified by using an analytical assessment approach for masonry buildings. 
The main aim of this paper is to compare the damage suffered by the two historic centres Norcia and Amatrice under the two main events of the 2016 Central Italy earthquake sequence, by considering the increased seismic demand to structures experiencing repeated shakings. This paper presents in section 2 the methodology adopted and the steps followed to determine the damage-state dependent capacity curves; in section 3 a brief description of the two main events of the sequence considered in this study, the $24^{\text {th }}$ of August $M_{w} 6.2$ and the $30^{\text {th }}$ of October $M_{w}$ 6.5 events. Section 4 is dedicated to the description of the two building stocks of Norcia and Amatrice. In section 5, the derived bilinear capacity curves for each of the buildings of the two datasets undergoing the spectra of the two shocks are presented in terms of performance points. A discussion on the results in terms of fragility functions concludes the paper.

\section{PROPOSED METHODOLOGY}

The proposed procedure to assess the cumulative damage of existing masonry structures exposed to repeated shaking can be summarized as shown in Figure 1.

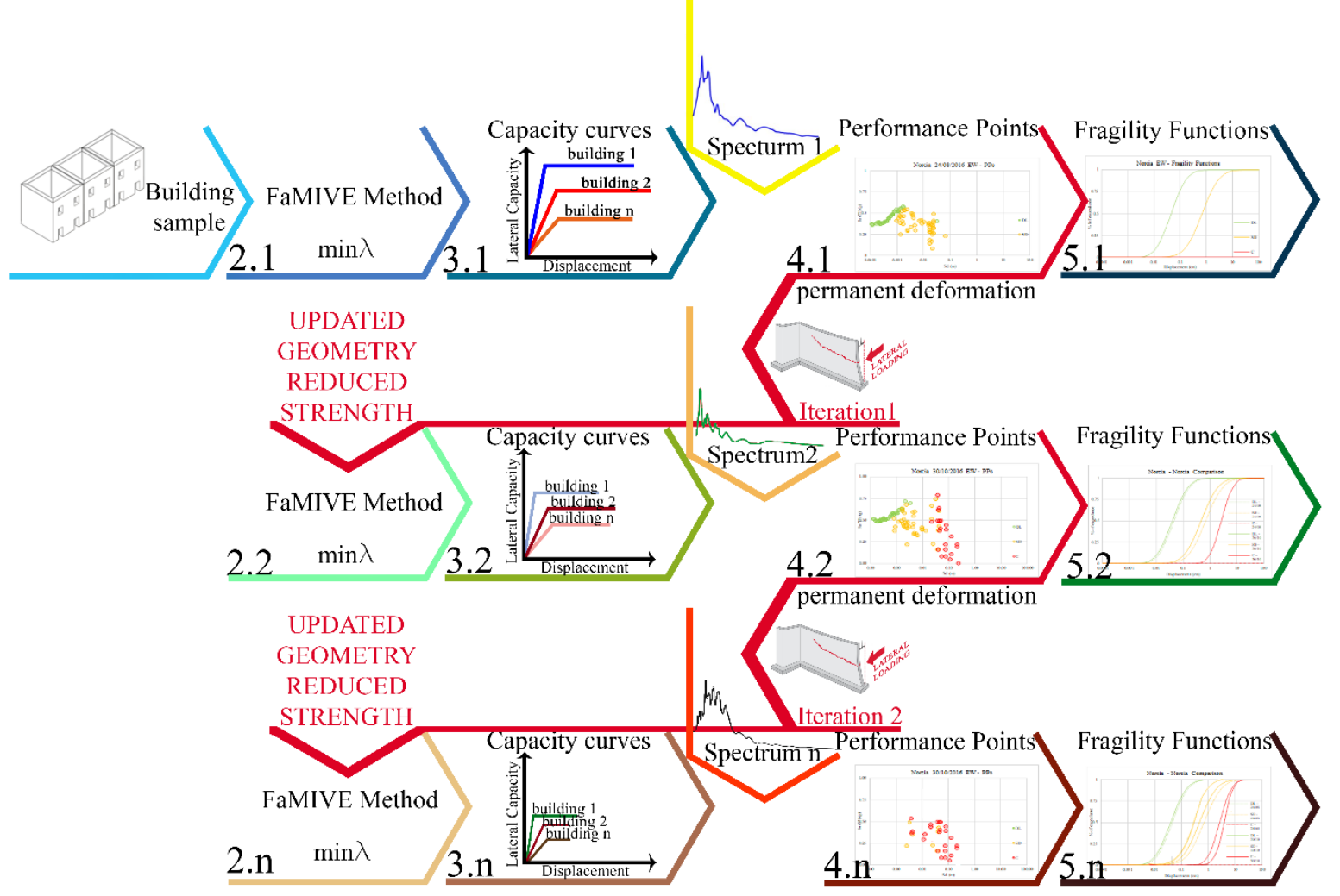

Figure 1: Proposed methodology to assess the cumulative damage to masonry structures

Step (1) consists in the definition of a representative building sample, able to exhaustively represents the variety of building typologies of the case study under consideration. Section 3 explain how the buildings are chosen in the two cases presently analysed.

Step (2) is to choose an appropriate analytical assessment procedure able to evaluate the seismic vulnerability of the two samples. The procedure used in this work is the macro-element modelling approach FaMIVE [17], which allows to analyse a large number of buildings in a short time, producing simplified capacity curves based on ultimate lateral strength capacity and elastic and ultimate displacement. Having chosen suitable strong motion records, a capacity spectrum approach, such as N2 [18], can then be applied to determine the performance point for each capacity curve, representative of the response of each façade [19]. 
One of the main advantages of the FaMIVE method, is the possibility to tailor the routines to include specific characteristics of the building stocks considered which affect the mechanisms that might develop. A new module accounting for the effects of ring beams has been developed and included in the calculations. The work from [20] was used and further developed to correctly represent the current case studies. Specific assumptions on the way the ring beams are connected to the walls were implemented following the post-earthquake on site observations.

The procedure calculates the collapse load factor $(\lambda)$ associated to all possible in plane (IP), out-of-plane (OOP), and combined (COM) failure mechanisms, then choses the one with the minimum $\lambda$, associated with the most damaging consequences for the analysed facade. The collapse load factor determines the lateral acceleration capacity of the structure.

The bilinear capacity curves are defined for each façade on the basis of three couple of points: $(0,0),\left(a_{u}, k^{*} D_{y}\right),\left(a_{u}, D_{u}\right)$, where $a_{u}$ represents the ultimate strength capacity and is defined as the ratio $\lambda / \alpha$, namely the collapse load factor and the proportion of façade involved in the mechanism; the elastic limit displacement $\mathrm{D}_{\mathrm{y}}$ is dependent on the natural period of the façade, which accounts for the presence of concrete ring beams, and the yielding strength $A_{y}$ which is the value of acceleration which will cause the stress distribution of the critical cross section to be triangular (elastic limit). The factor $\mathrm{k}$ accounts for the difference between the initial elastic limit and the idealization of the curve, depending on each mechanism type. Finally, $\mathrm{D}_{\mathrm{u}}$ represents the ultimate displacement of the façade considered. This is defined as a proportion of the displacement that determines the collapse of the façade $\left(D_{c}\right)$ and is defined in relation to the occurring failure mechanism (i.e. IP, OOP or COM). More specifically, this is given as the ultimate displacement occurring at the resisting section of the wall (i.e. the effective proportion of the wall thickness in the case of OOP, the proportion of wall thickness and staggering ratio in the case of COM, the minimum value between staggering and wall thickness for IP).

The following step (3) is to compare each of the bilinear curve to the natural records of the events of interest in terms of spectral acceleration and displacement. Further information on the two main shocks considered in this study is given in Section 4. The outcome of this interpolation results is a cloud of representative performance points, Step (4), which, when compared with predetermined damage thresholds, defines the damage state of each façade of the sample undergoing the specific event. The final step (5) is to determine fragility functions for different limit states by using median and standard deviation values of the limit state displacement and deriving lognormal cumulative distributions. Three limit states are considered in agreement with the three representative points of the capacity curves, namely 1) damage limitation 2) structural damage and 3) collapse.

The novelty of the method lies in the way in which the cumulated damage due to consecutive strong shaking events is accounted for. The spectral displacement calculated to find the first set of performance points after the first event (i.e. interpolation with the first spectrum), is taken as permanent drift of each façade and used to determine its new stiffness and natural period. Moreover, the permanent drift is also accounted for as permanent leaning reducing the capacity of the structure to withstand further flexure caused by lateral acceleration, hence affecting the strength capacity determined by a new $\lambda$ factor. Each of the new capacity curves so constructed is interpolated with the representative record of the new event in the sequence, to obtain a new performance point which accounts for the previous damage condition.

This should be repeated for different building samples, for different spectra recorded at different locations for the same event. Depending on the number of iterations, which refer to the number of events considered, it is possible to observe a shift in both capacity and fragility functions, which clearly indicates the change in the overall sample' capacity due to repeated shocks. 


\section{NORCIA AND AMATRICE'S BUILDING STOCKS}

During two consecutive EEFIT field missions the authors conducted two on-site investigations in Norcia and Amatrice and carried out a detailed post-event survey. Given the extensive level of damage observed in Amatrice and the very restricted time allowance within the red zone, it was preferred to collect very detailed chains of $360^{\circ}$ images to document the damage condition of the building constructions along the main Corso Umberto I (East-West) and the perpendicular street (North-South) [8]. On the contrary, the damage condition of the residential buildings in Norcia was limited, allowing to conduct a detailed survey for a set of 82 buildings, corresponding to 110 facades (hereafter defined as N_sample) [6]. The sample was purposely chosen to evenly match the variety of buildings' heights observed: more specifically, $74 \%$ of the sample is made of two-storeys buildings, with the remaining $26 \%$ distributed between threestoreys (18\%) and one-storey (8\%). Given the similarities in building size and structural systems between the two historic centres [7], a 'simil' sample of the Norcia dataset was modified to represent the Amatrice build-ing stock in terms of material properties, number of storeys, horizontal structures (roof and flooring types) and traditional restraining elements applied (hereafter defined as A_sample), as obtained by the onsite ODC survey [8]. N_sample is characterized by $70 \%$ of buildings with a medium-high quality of masonry (M2), 17\% of buildings made with a high quality of masonry (M1) and the remaining $13 \%$ of buildings characterized by a poor-quality masonry (M3). A_sample is characterized by $80 \%$ of the buildings with a poor-quality masonry (M3) and $20 \%$ of buildings with a medium-high quality (M2). Since no information is available to date on the mechanical properties test values for local masonry construction, relevant reference values are taken from Table C8A.2.2. of the NTC08 [22], summarised in Table 1, for the masonry fabrics identified on site.

\begin{tabular}{ccccc}
\hline Masonry Typologies & $\begin{array}{c}\mathrm{f}_{\mathrm{m}} \\
\left(\mathrm{N} / \mathrm{mm}^{2}\right)\end{array}$ & $\begin{array}{c}\tau_{0} \\
\left(\mathrm{~N} / \mathrm{mm}^{2}\right)\end{array}$ & $\begin{array}{c}\mathrm{E} \\
\left(\mathrm{N} / \mathrm{mm}^{2}\right)\end{array}$ & $\begin{array}{c}\text { Weight } \\
\left(\mathrm{kg} / \mathrm{m}^{3}\right)\end{array}$ \\
\hline Dressed rectangular stone masonry (M1) & 6.0 & 0.090 & 2400 & 22 \\
& 8.0 & 0.120 & 3200 & \\
Cut Stone with good bonding (M2) & 2.6 & 0.056 & 1500 & 21 \\
& 3.8 & 0.074 & 1980 & \\
Irregular stone masonry (pebbles) (M3) & 1.0 & 0.020 & 690 & 19 \\
& 1.8 & 0.032 & 1050 & \\
\hline
\end{tabular}

Table 1: Masonry types used in the case studies, retrieved from [22]

Given the general difference in fabric and mortar quality between the two towns' buildings, the upper bound values of E (Young Modulus) were used to identify the characteristics of Norcia's masonry typologies, while the lower bound were used to identify the ones of Amatrice. In a similar manner the values of cohesion $\tau_{0}$ have been assigned. Figure 2 a) b) and c) show examples of masonry observed in Norcia, representative of the three typologies.

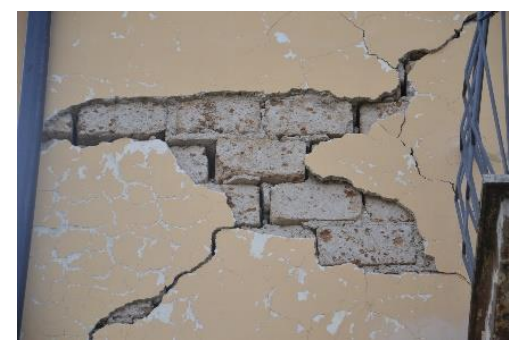

a)

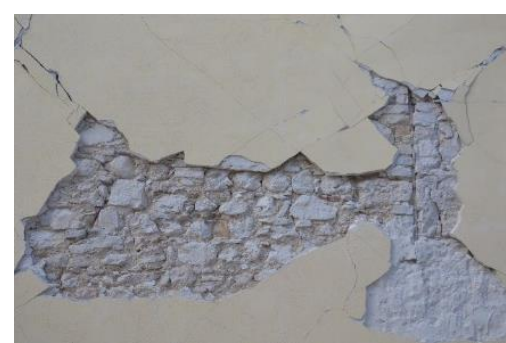

b)

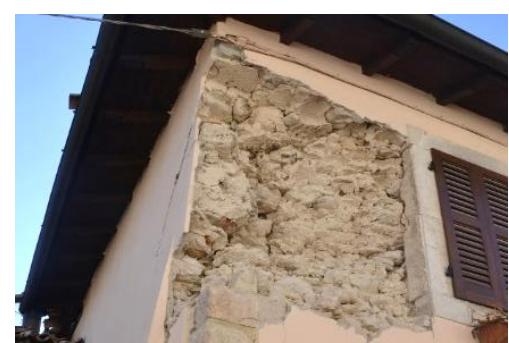

c)

Figure 2: Details of the M1, M2 and M3 masonry types in Norcia 
Owing to the widespread level of damage in Amatrice, it was possible to observe the inner layers and the lack of connection in the thickness of the walls (Figure 3a)). The majority of buildings were made of poorly dressed stones, mostly irregular and characterized by bad quality of mortar as shown in Figure $3 \mathrm{~b}$ ). Very often, the walls were covered with thick layers of wired mesh and concrete jacketing [7], that would help bond the units together. Table 2 summarizes the key parameters characterizing the two building stocks.

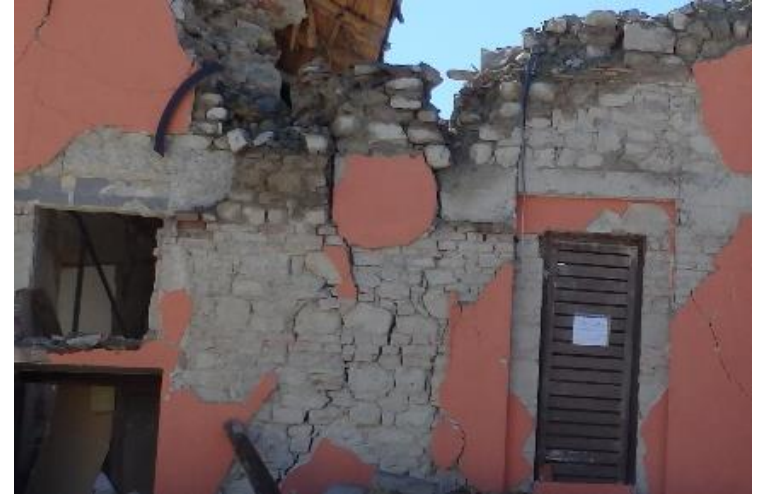

a)

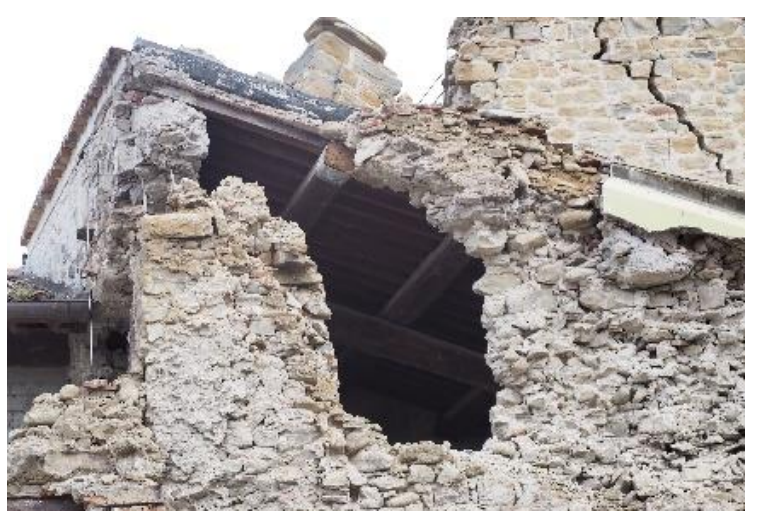

b)

Figure 3: Details of the M2 and M3 masonry types in Amatrice

Given the limited number of collapsed buildings in Norcia, the inspection of the horizontal structures was only partially possible, therefore the information regarding this specific aspect of the building stocks' characterization refers to [23]. The three main flooring typologies encountered were wooden floors (WF) made of traditional joists, barrel vaults (VF) and reinforced wooden floors (RWF). In the case of Amatrice, additional presence of concrete floor slabs (CF) is added to the list, as these have been observed on site and reported in Figure 4 a) and b).

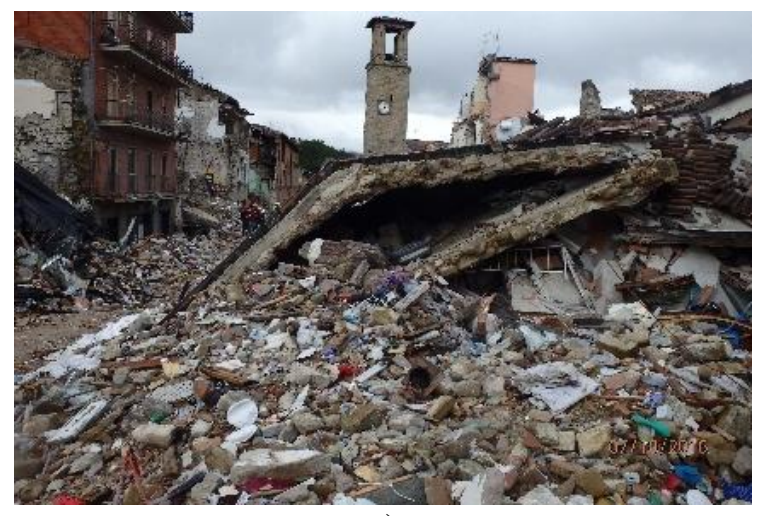

a)

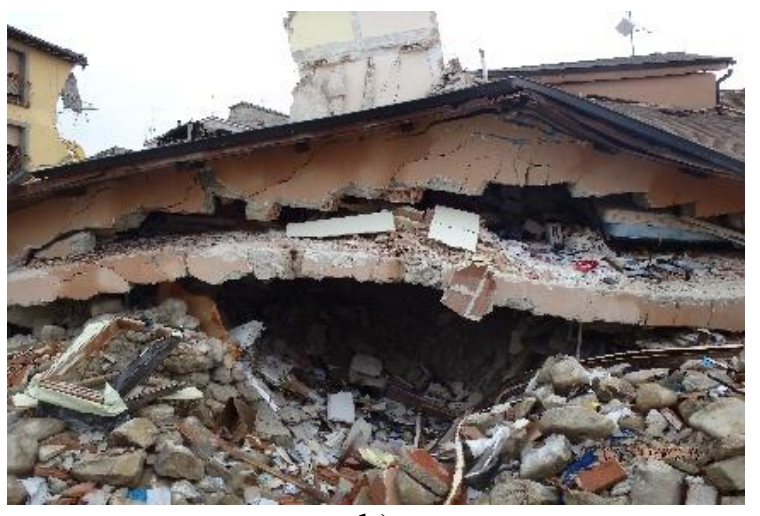

b)

Figure 4: Details of the concrete slabs observed in Corso Umberto I - Amatrice

For the roof structures, the more traditional case of timber joists with screed and tiles (R1) was found only in $20 \%$ of the sample, while the remaining $80 \%$ showed to have roofs made with concrete slabs (R2) [23]. These typologies were implemented following the post-1979 building prescriptions listed within the Regional Law no.34 1981, enacted after the Irpinia earthquake [6]. While on site, it was possible to observe the lack of connection between these elements and the underneath masonry walls as shown in Figure 5 a), taken in Amatrice and 
Figure b) taken in Norcia. With reference to the restraining elements, more traditional provisions such as buttresses (B) shown in Figure 5 a), ties (T) in Figure 5 b) were observed in Norcia, together with a number of buildings showing concrete ring beams (RB) (Figure $5 \mathrm{c}$ )).

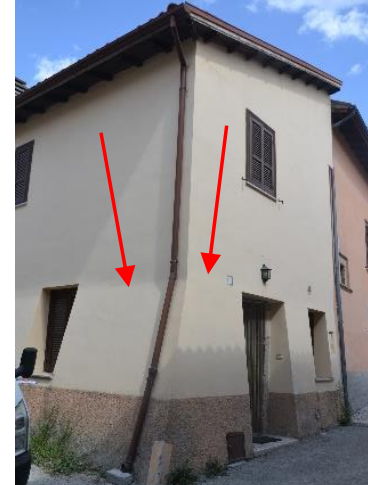

a)

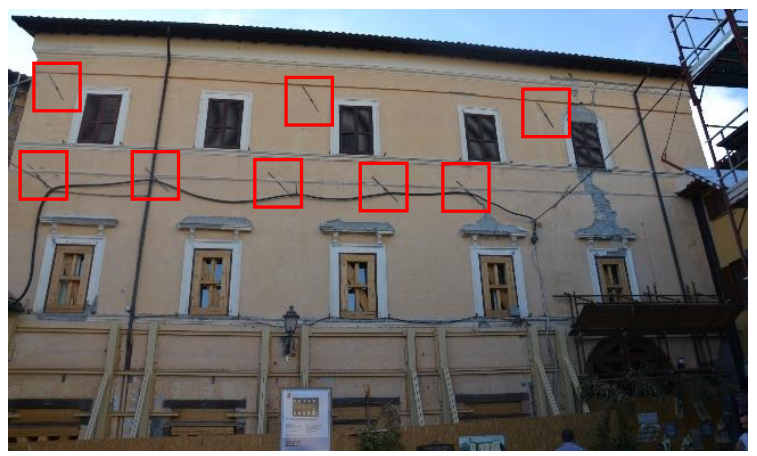

b)

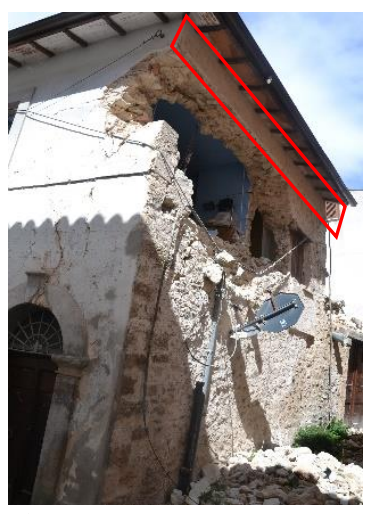

c)

Figure 5: Restraining elements observed in Norcia: a) buttresses, b) ties o c) concrete ring beams

Conversely during the site investigation, no buttresses were observed in Amatrice. The main building stocks' characteristics are summarized in Table 2

\begin{tabular}{ccccc}
\hline Building Stock & Masonry Type & Floor Type & Roof Type & Restraining elements \% \\
\hline N_sample & M1 17\% & WF-VF 35\% & R2 80\% & T 25\% \\
& M2 70\% & RWF 65\% & R1 20\% & B 33 \% \\
& M3 13\% & & RB 65\% \\
A_sample & M2 30\% & WF-VF 35\% & R2 80\% & T 25\% \\
& M3 70\% & RWF 30\% & R1 20\% & RB 65\% \\
& & CF 35\% & \\
\hline
\end{tabular}

Table 2: Parameters implemented in the FaMIVE procedure to reproduce Norcia and Amatrice's building stocks.

In this section the characteristics of Norcia and Amatrice have been presented. The following section will describe the selected main shocks of the Central Italy sequence which have been considered relevant to describe the damage evolution of the two building stocks.

\section{THE TWO MAIN EVENTS OF THE CENTRAL ITALY SEQUENCE}

There are two different approaches to conduct seismic assessment at territorial scale that can be used to establish the seismic hazard of a region, namely probabilistic seismic hazard approach (PSHA) and deterministic scenario approach, directly correlated to the events occurred in the region. As discussed by [19], a deterministic approach might be more relevant for the assessment of historic centres, mainly because, if the seismicity of the area is well known, a credible and reliable earthquake scenario can be developed and be directly correlated to the building stock performance [24]. The 2016 Central Italy seismic swarm occurred in an area with the highest seismic hazard in Italy, where the PGA values expected with a probability of exceedance of $10 \%$ in 50 years are higher than $0.25 \mathrm{~g}$ [2][4]. The information on the records of the two events, extracted from the ESM database [20], are reported in Table 3: 


\begin{tabular}{ccccccc}
\hline $\begin{array}{c}\text { Station } \\
\text { Name }\end{array}$ & $\begin{array}{c}\text { Station } \\
\text { Code }\end{array}$ & Location & Longitude & Latitude & Soil Type & $\begin{array}{c}\text { Distance to } \\
\text { city centre }\end{array}$ \\
\hline Amatrice & AMT & Free Field & 42.63246 & 13.28618 & B & $0.9881 \mathrm{~km}$ \\
Norcia & NRC & Free Field & 42.79254 & 13.09648 & B & $0.1727 \mathrm{~km}$ \\
\hline
\end{tabular}

Table 3: Details of the recording stations

Acceleration response spectra are extracted from the ESM database [25] and shown in Figure 6 a) and 6 b) respectively showing the $24^{\text {th }}$ of August and the $30^{\text {th }}$ of October events recorded at both AMT and NRC stations.

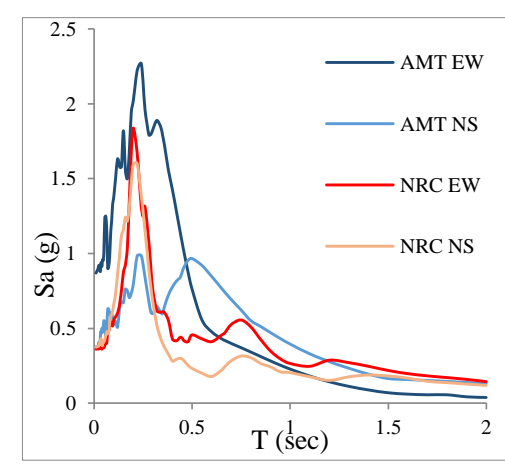

a)

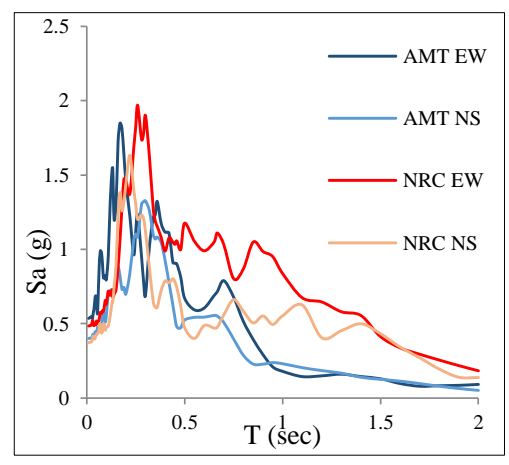

b)

Figure 6: Spectra of the 24/10/2016 event (a) and 30/10/2016 event (b) recorded at AMT and NRC stations

The August event (a) has the largest ever peak ground acceleration recorded on Italian soil at the Amatrice instrument. It is also characterized by large amplifications in the 0.1-0.5 s period range, with a large drop for larger values. On the contrary, the event of the $30^{\text {th }}$ of October (b) shows amplification in the medium period range, with accelerations exceeding $1.0 \mathrm{~g}$ for periods around 1.0, which can help explaining the collapse of all the churches in Norcia [1][4][7].

Very relevant to the understanding of the building stock performance in the two towns is the demand in terms of spectral displacement imposed by the two seismic shocks considered as shown in Figure 7 a). For natural period lower than $0.5 \mathrm{~s}$, the Amatrice record of the first event shows values of displacement demand up to $60 \mathrm{~mm}$, while the demand recorded by the NRC instrument is in the range of $20 \mathrm{~mm}$.

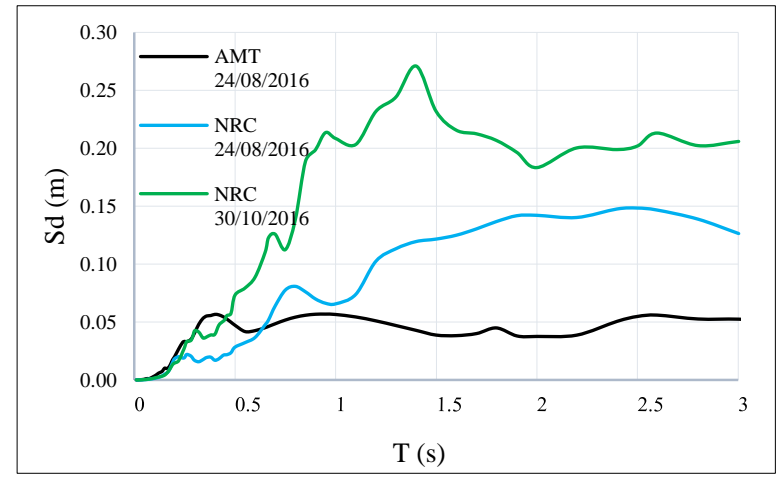

a)

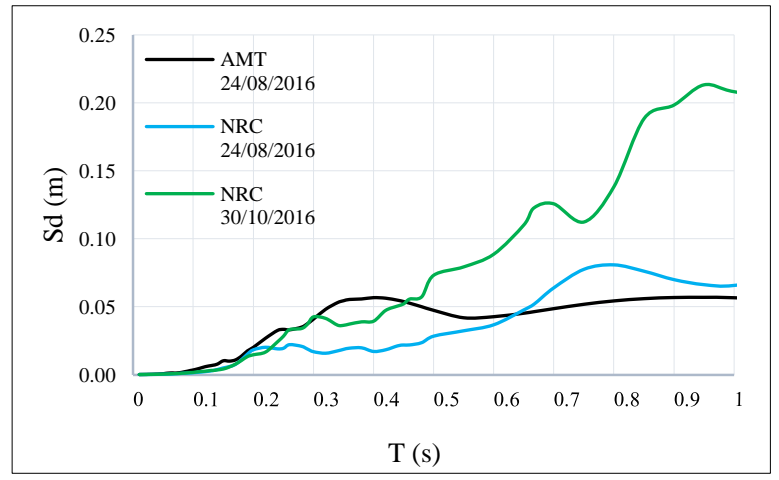

b)

Figure 7: Seismic demand in terms of spectral displacement for: a) the 24/08/2016 event with records from AMT and NRC station and the 30/10/2016 event with record from NRC station and b) close up of the same records in the range of $0<\mathrm{T}_{1}<1 \mathrm{~s}$ 
A close up in the range of $0<\mathrm{T} 1<1 \mathrm{~s}$ [reported in Figure 7b)], which contains $97 \%$ of the two building samples natural periods, shows that for values of up to $0.5 \mathrm{~s}$ ( $85 \%$ of the building samples), the displacement demand of the 24th August event in Amatrice was substantially greater than the one in Norcia, while the 30/10/2016 event imposed on the Norcia building stock a demand twice as large as the one in August.

\section{RESULTS AND DISCUSSION}

The effect of the main shocks of the two events of $24^{\text {th }}$ August 2016 and $30^{\text {th }}$ October $2016^{\text {th }}$ are represented in terms of performance points obtained by applying the $\mathrm{N} 2$ procedure [18] and computing their cumulative distribution to produce fragility functions with respect to three damage limit states: damage limitation, structural damage and collapse in accordance to EC8 part 3 [3]. For the present study, the EW direction of the earthquake ground motion record is used for both events, as this results in the highest demand on the two building samples.

Figure 8 a) shows the cloud of performance points representative of all the facades of the A_sample subjected to the $24^{\text {th }}$ August 2016 event, and Figure 8 b) the corresponding fragility functions.

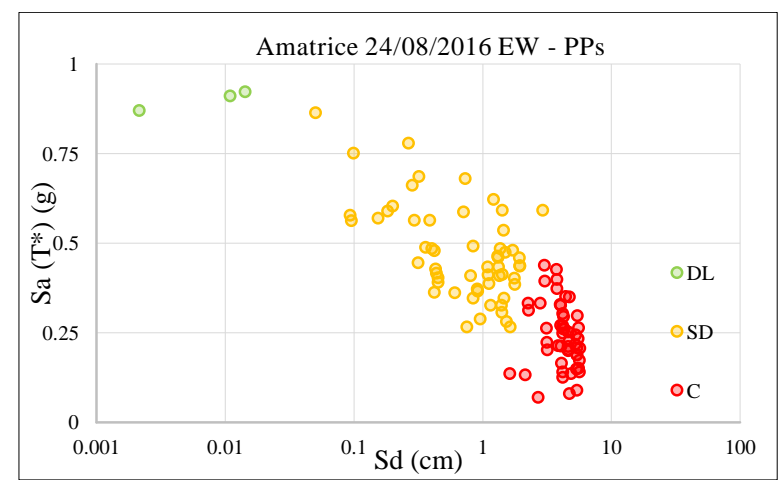

a)

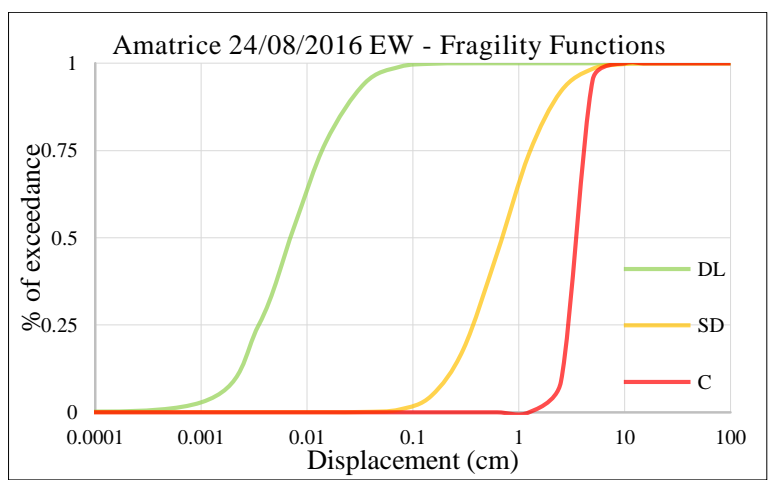

b)

Figure 8: Performance points (a) and Fragility Functions (b) for Amatrice after the 24/08/2016 event

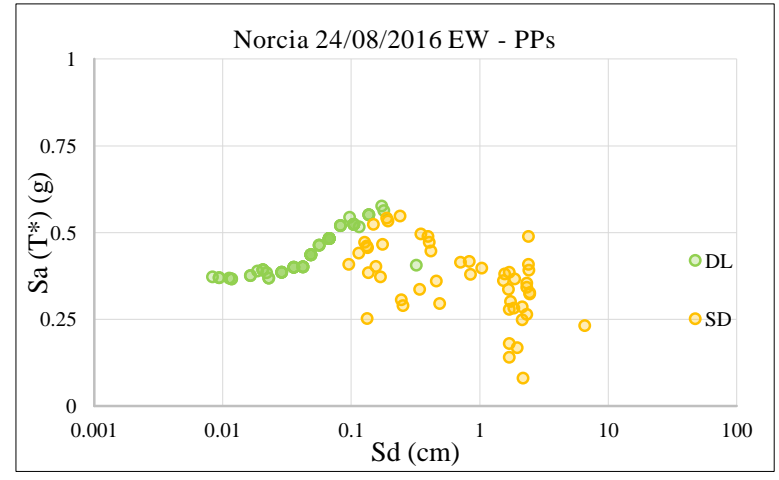

(a)

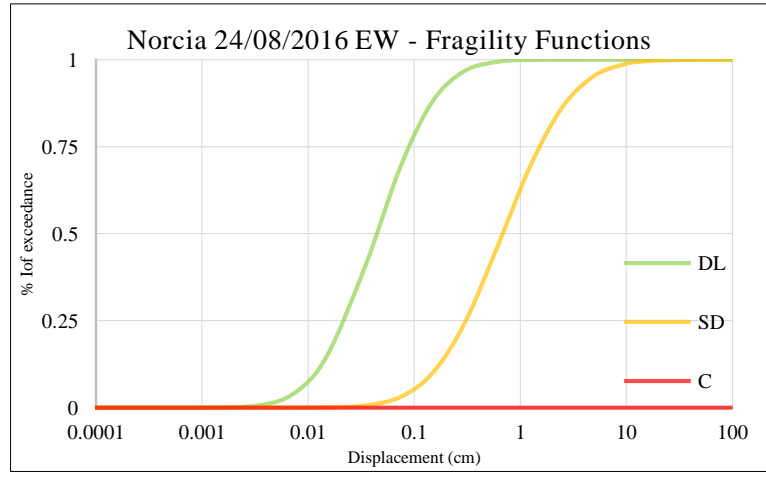

(b)

Figure 9: Performance points (a) and Fragility Functions (b) for Norcia after the 24/08/2016 event

Figure 9 a) and b) show the performance of N_sample and related fragility functions for the same event. shows that the distribution of damage limitation performance points for A-sample is confined to very modest lateral displacement, when compared with the N_sample. This is due to the substantially greater strong ground motion experienced, but also to the stiffer and lower strength capacity of the A_sample with respect to the N_sample. This is confirmed by 
the much narrower range of strength demand for the N_sample $(0.08 \mathrm{~g}$ to $0.57 \mathrm{~g})$ when compared to the A_sample $(0.07 \mathrm{~g}$ to $0.92 \mathrm{~g}$ ) for a similar range of displacement demand. It should be also noted that the performance points for collapse for A_sample are confined within a narrow range corresponding to the limit ultimate displacement of their capacity curves, which in turn is a function of the masonry units' size and masonry quality. No collapse was computed for the N_sample.

Figure 10 a) shows the proportions of buildings in each damage state after the August event in each of the two town, providing a good correspondence to the empirical onsite observations. Figure $10 \mathrm{~b}$ ) compares the corresponding fragility functions. While the structural damage condition is not substantially different for the two samples, the larger proportion of buildings with buttresses and ties, coupled with the lower level of acceleration and displacement demand for the lower period range, ensure a much better performance of the N_sample with respect to the damage limitation threshold.

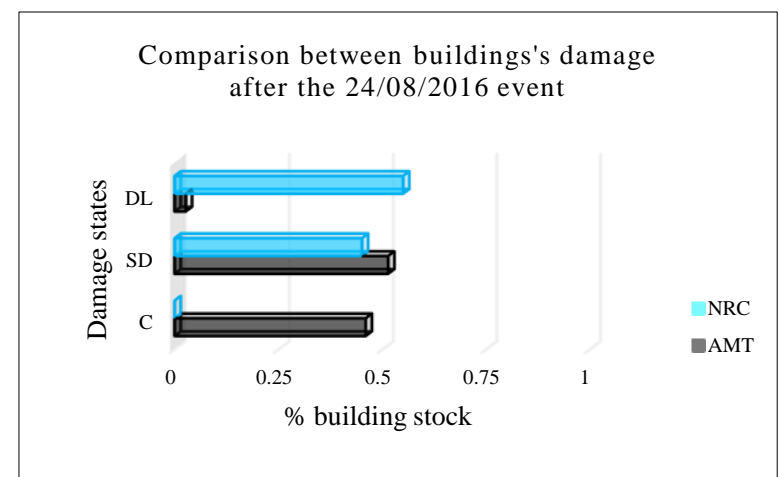

(a)

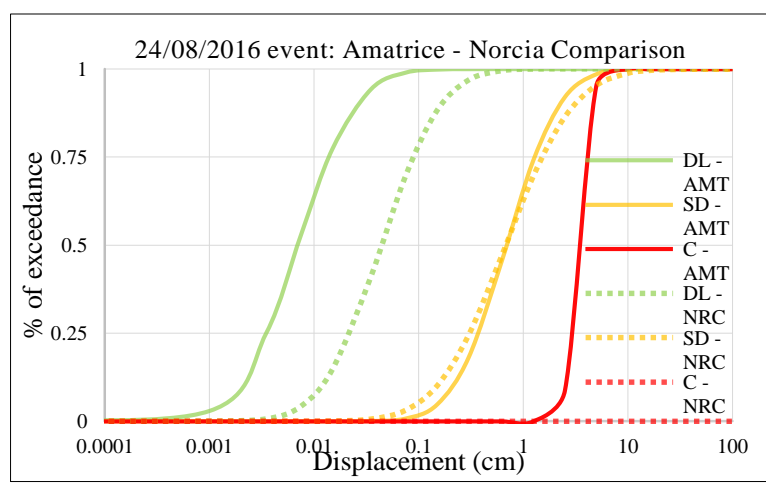

(b)

Figure 10: Comparison between the \% of building stocks' damage (a) and the two sets of fragility functions (b) for the 24/08/2016 event.

\begin{tabular}{|c|c|c|c|}
\hline $\begin{array}{c}\text { Building Stock } \\
\text { Event }\end{array}$ & Damage state & Median $(\theta)$ & Standard deviation $(\beta)$ \\
\hline \multirow{3}{*}{$\begin{array}{l}\text { A_sample } \\
24 / 08 / 2016\end{array}$} & $\mathrm{DL}$ & 0.011 & 1.023 \\
\hline & SD & 0.912 & 0.915 \\
\hline & $\mathrm{C}$ & 3.542 & 0.228 \\
\hline \multirow{3}{*}{$\begin{array}{c}\text { N_sample } \\
24 / 08 / 2016\end{array}$} & DL & 0.049 & 1.032 \\
\hline & SD & 0.839 & 1.182 \\
\hline & $\mathrm{C}$ & - & - \\
\hline \multirow{3}{*}{$\begin{array}{l}\text { N_sample } \\
30 / 10 / 2016\end{array}$} & DL & 0.038 & 1.086 \\
\hline & SD & 0.422 & 1.198 \\
\hline & $\mathrm{C}$ & 3.358 & 0.811 \\
\hline
\end{tabular}

Table 4: Values of median and standard deviation characterizing the two samples under the 24/08/2016 and the 30/10/2016 event.

Table 4 shows the values of mean $(\theta)$ and standard deviation $(\beta)$ of both samples after the August 2016 event, and for the N_sample after the $30^{\text {th }}$ October event, for each damage state. Figure $11 \mathrm{a}$ ) and $11 \mathrm{~b}$ ) show the condition of the $\mathrm{N} \_$sample after the $30^{\text {th }}$ October event. The performance points and fragility curves presented are obtained by running a second iteration to the N_sample of Figure 9 a) as described in section 2.

Notwithstanding the clear increase in terms of lateral spectral acceleration demand $\mathrm{Sa}\left(\mathrm{T}^{*}\right)$, which now reaches $0.75 \mathrm{~g}$, there is still a significant proportion of buildings remaining within 
the DL state. However, the distribution of performance points in SD is much sparser, and almost $20 \%$ of the buildings enter the collapse state. The cloud of performance points has a general shift towards the right, indicating that the displacement demand has increased: some of the points reach collapse for $20 \mathrm{~cm}$ displacement against the $6.5 \mathrm{~cm}$ recorded after the August event.

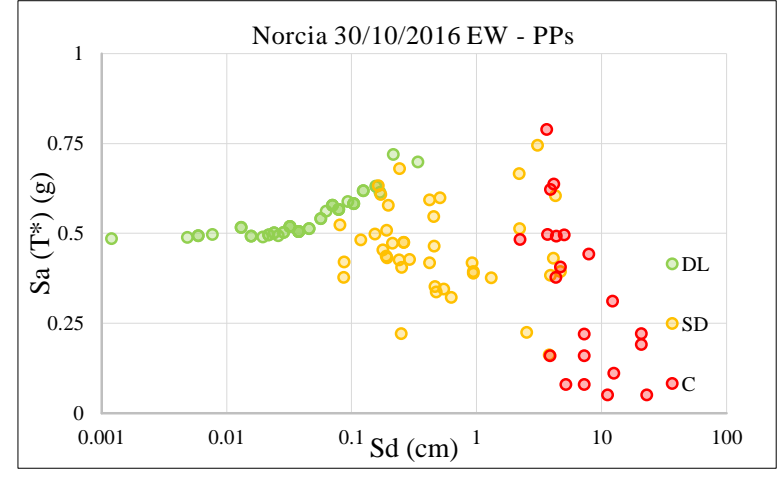

(a)

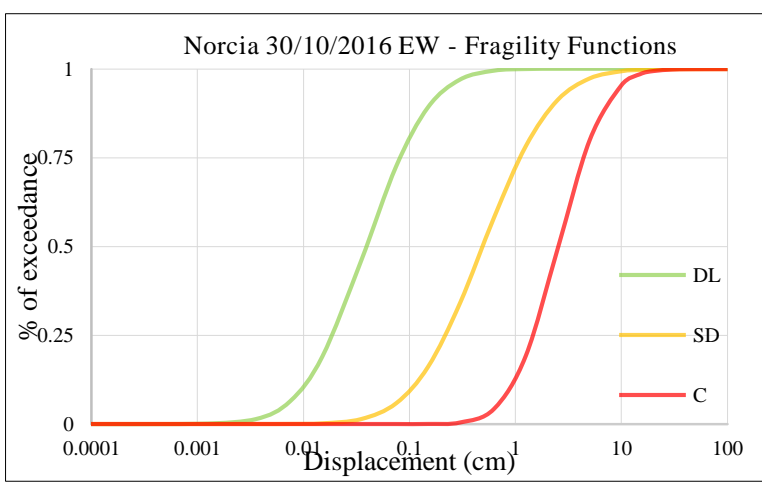

(b)

Figure 11: Performance points (a) and Fragility Functions (b) for Norcia after the 30/10/2016 event

Figure 12 a) and b) show the comparison of the status of N_sample after the first and second event, respectively. Beside the evident presence of collapses, the fragility functions for lesser damage states are shifted towards the left, as the residual values of the damage thresholds for each damage state is smaller than in the buildings exposed to the first event, and they have greater variability. Such shift is evident in the reduction of the median $(\theta)$ values and increase of the standard deviation $(\beta)$ of the N_sample for the two events, summarised in Table 4.

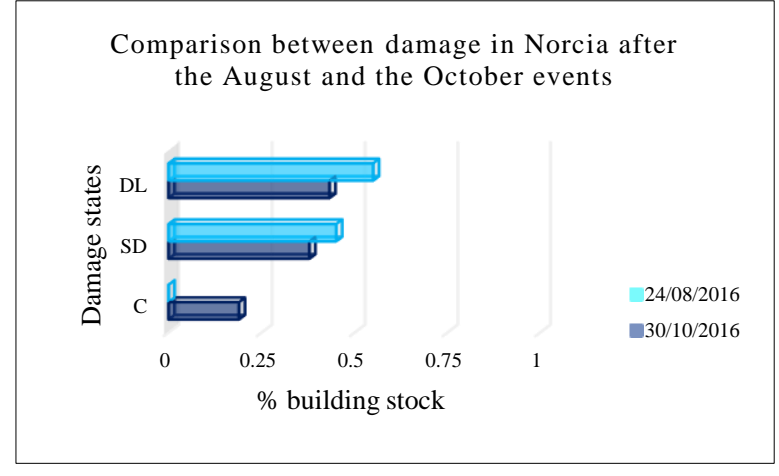

(a)

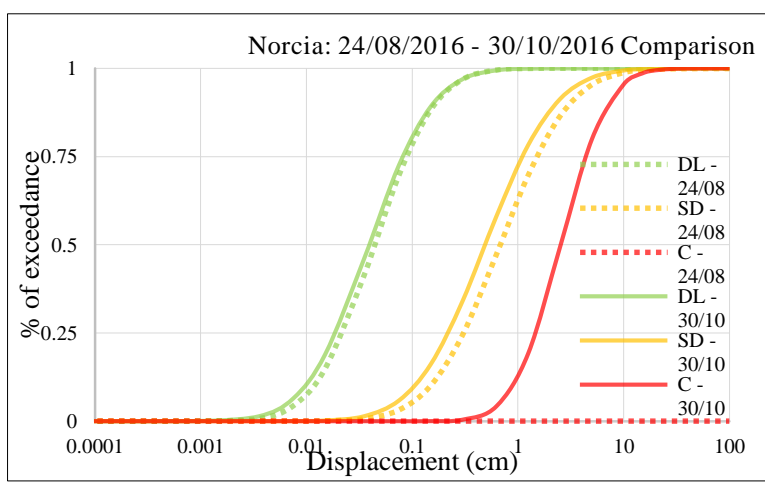

(b)

Figure 12: Comparison between percentages of Norcia building stock's damage between the two seismic events (a) and the two sets of fragility functions (b) for the 24/08/2016 and the 30/10/2016 events.

\section{CONCLUSIONS}

A limit state analysis of two samples representative of the two building stocks of Amatrice and Norcia, affected by the 2016/2017 Central Italy earthquake sequence has been conducted using the FaMIVE approach and N2 method, with the aim of assessing their seismic capacity and cumulated damage when exposed to sequences of high shaking, without being repaired. To this end a simple methodology has been developed whereby the masonry structures are characterized by bilinear curves and a capacity spectrum approach s adopted to compute performance point, using the natural spectra recorded at the sites for the various events. 
Two samples with similar geometries and different mechanical characteristics are created on the basis of an accurate survey conducted in Norcia, and analysis of extensive omnidirectionalal camera records collected in Amatrice. The approach is successful in delivering buildings samples representative of the two diverse building stock. The extents of damage observed on site have been captured by the analytical method chosen and satisfactorily simulated via the determination of performance points and the derivation of fragility curves. The use of updated flexibility, reduced ductility and residual damage thresholds successfully capture the damage evolution through the two main events of the seismic sequence. The updated fragility functions show reduced median, higher standard deviation and an increase in damage probability of about $15 \%$ for the structural damage state.

\section{Acknowledgements}

The Authors wish to thank the Civil Protection Department of the Umbria Region and especially Nicola Berni and Paolo Putrino, the University of Perugia and Ferrara, Professor Antonio Borri, Professor Andrea Giannatoni, Dr Giulio Castori, Dr Romina Sisti and Dr Alessandro De Maria for their insights to the case study of Norcia. Miss Chen Huang is thankfully acknowledged for the support given during the Sept 2017 EEFIT Research mission.

\section{REFERENCES}

[1] Sorrentino, L., Cattari, S., da Porto, F., Magenes, G., Penna, A. (2018) Seismic behaviour of ordinary masonry buildings during the 2016 central Italy earthquakes. Bull Earthquake Engineering, 2018.

[2] Gruppo di Lavoro INGV sul terremoto in Centro Italia, Summary report on the October 30, 2016 earthquake in central Italy $\mathrm{M}_{\mathrm{w}} 6.5,2016$.

[3] CEN, Eurocode 8: Design of structures for earthquake resistance - Part 3: Assessment and retrofitting of buildings. Brussel, EN 1996-1-1:2005

[4] Sextos A., et al, Local Site Effects and Incremental Damage of Buildings During the 2016 Central Italy Earthquake Sequence, Earthquake Spectra 34:4, 1639-1669, 2018

[5] Locati, M., Camassi, R., Rovida, A., Ercolani, E., Bernardini, F., Castelli, V., ... INGV. Database Macrosismico Italiano, versione DBMI15, 2016 [in Italian]

[6] Putrino, V., D’Ayala, D., Effectiveness of seismic strengthening to repeated earthquakes in historic urban contexts: Norcia 2016, Disaster Prevention and Management, 10.1108/DPM-07-2018-0230, 2019.

[7] D’Ayala D., Faure-Walker, J., Mildon, Z., Lombardi, D., Galasso, C., Pedicone, D., Putrino, V., Perugini, P., De Luca, F., Del Gobbo, G., Lloyd, T., Morgan, E., Totaro, A., Alexander, D., Tagliacozzo, S., The $\mathrm{M}_{\mathrm{w}} 6.2$ Earthquake of $24^{\text {th }}$ of August 2016. A field report by EEFIT, available at https://www.istructe.org/resources-centre/technical-topicareas/eefit/eefit-reports, 2019.

[8] Stone H., Putrino V., D’Ayala D., Earthquake Damage Data Collection Using Omnidirectional Imagery, Frontiers Built Environment. 4:51, 2018

[9] J. Ruiz-García, J.C. Negrete-Manriquez, Evaluation of drift demands in existing steel frames under as-recorded far-field and near-fault mainshock-aftershock seismic sequence, Engineering Structures, 33(2), 621-634, 2011.

[10] Chien-Kuo Chiu, Reliability-based service life assessment for deteriorating reinforced concrete buildings considering the effect of cumulative damage, Structure and Infrastructure Engineering, 10:9, 1101-1118, DOI: 10.1080/15732479.2013.793722, 2014. 
[11] N. Nazari; J. W. van de Lindt, Y. Li, Effect of Mainshock-Aftershock Sequences on Woodframe Building Damage Fragilities Journal of Performance Constructed Facilities, 29(1): 04014036, 2013.

[12] Iervolino, I., Giorgio, M., Chioccarelli, E., Markovian modelling of seismic damage accumulation. Earthquake Engineering Structural Dynamic, 45, no. 3: 441-461, 2016.

[13] Jalayer, F., Asprone, D., Prota, A., Manfredi, G., A decision support system for postearthquake reliability assessment of structures subjected to aftershocks: an application to L'Aquila earthquake, 2009, Bull Earthquake Engineering, 9, 997-1014, 2011.

[14] Mouyiannou, A., et al, (2014) Implication of cumulative seismic damage on the seismic performance of masonry buildings, Bulletin of the New Zealand Society for Earthquake Engineering, Vol 47, no.2, June 2014.

[15] Grimaz, S., Malisan P, (2017) How could cumulative damage affect the macroseismic assessment?, Bull of Earthquake Engineering, 15, 2465-2481, 2017.

[16] F. Mollaioli, O. AlShawa, L. Liberatore, D. Liberatore, L. Sorrentino, (2018), Seismic demand of the 2016-2017 Central Italy earthquakes, Bull of Earthquake Engineering, https://doi.org/10.1007/s10518-018-0449-y

[17] D’Ayala, D., Speranza, E., Definition of Collapse Mechanisms and Seismic Vulnerability of Historic Masonry Buildings, Earthquake Spectra, 19(3), 479-509, 2003.

[18] Dolsek, M., Fajfar, P., Simplified non-linear seismic analysis of infilled reinforced concrete frames, Earthquake Engineering Structural Dynamics, 34(1), 49-66, 2004.

[19] Novelli, V., D’Ayala, D., Makhloufi, N., Benouar, D., Zekagh, A., A procedure for the identification of the seismic vulnerability at territorial scale. Application to the Casbah of Algiers, Bull Earthquake Engineering, 13, 177-202, 2015.

[20] Beolchini, G., Cifrani, G., Girotti Pucci, G., Catalino, S., Spuri, C., Corazza, L., Martinelli, A., Repertorio dei meccanismi di danno, delle tecniche di intervento e dei relativi costi negli edifici in muratura, Marche Region,University of L'Aquila and CNR-ITC, 2002 (in Italian)

[21] D'Ayala, D., Force and displacement-based vulnerability assessment for traditional buildings, Bull Earthquake Engineering, 3(3), 235-265, 2005.

[22] NTC, Linee Guida, Norme tecniche per le costruzioni, Italian Technical Norms for Consturctions, 2008

[23] Borri, A., Sisti, R., Prota, A., Di Ludovico, M., Costantini, S., Barluzzi, M., De Maria, A., Aisa,e., Bragetti, A., Savi, F., Fagotti, G., Baldi, L., Analisi dell efficacia degli interventi realizzati su edifici del centro storico di Norcia colpiti dai sismi del 2016, 17th Italian National Conference on Earthquake Engineering, Pistoia, 17-21 September, SG13.253-266, 2017.

[24] D'Ayala, D., Ansal, A., Non-linear push over assessment of heritage buildings in Istanbul to define seismic risk, Bull Earthquake Engineering, 10(1), 285-306, 2012.

[25] Luzi L., Puglia R., Russo E. \& ORFEUS WG5 (2016). Engineering Strong Motion Database, version 1.0. Istituto Nazionale di Geofisica e Vulcanologia, Observatories \& Research Facilities for European Seismology. doi: 10.13127/ESM 